\title{
ВЛИЯНИЕ РАЗЛИЧНЫХ РЕЖИМОВ ТЕРМООБРАБОТКИ НА УДАРНУЮ ВЯЗКОСТЬ МЕТАЛЛИЧЕСКОГО СЛОИСТОГО КОМПОЗИТА (МСК) НА ОСНОВЕ СТАЛИ 3 И МЕДИ М1
}

\author{
В.Н. Воеводин, Н.И. Ильченко, А.Ю. Ростова, Е.А. Крайнюк, О.Н. Ильченко \\ Национальный научный центр «Харьковский физико-технический институт», \\ Харьков, Украина \\ E-mail: ilchenko_ni@ukr.net
}

Изучено влияние предварительной термической обработки на твердость, ударную вязкость и прокаливаемость металлического слоистого композита на основе стали 3 и меди М1. Были проведены исследования микроструктуры полученных композитов.

\section{ВВЕДЕНИЕ}

Применение металлических слоистых композитов (МСК) из разнородных металлов в конструкциях, испытывающих действия повышенных динамических нагрузок и температур, требует изучения особенностей разрушения металлического слоистого композита после различных термических обработок:

- отжига;

- закалки плюс отпуск.

Изучению закономерностей влияния термообработки на механические свойства и микроструктуру посвящено немало работ, но лишь для определенных марок сталей. Для МСK закономерности влияния изучены недостаточно. Работы чаще посвящены наноразмерным толщинам (менее 50 мкм) [1-6].

Предъявляемые требования к изделиям из металлических слоистых композитов предполагают разработку МСК с улучшенным комплексом физико-механических свойств. Последние во многом зависят от исходных компонент, их объемной доли, растворимости друг в друге, образования интерметаллидов, фаз и т. д., характера и закономерностей формирования структуры металлов, особенно в зоне их соединения $[1,7,8]$.

Целью данной работы является изучение механических свойств и структуры МСК на основе стали 3 и меди M1 после различных температурных режимов термообработок.

\section{МАТЕРИАЛЫ И МЕТОДИКА ИССЛЕДОВАНИЯ}

В данной работе испытывали образцы МСК, состоящего из семи слоев на основе стали 3 и меди M1 (таблица), которые получены методом горячей прокатки в вакууме $[9,10]$.
Технологический цикл получения МСК включал сварку в вакууме, отжиг при $850{ }^{\circ} \mathrm{C}$ (1 ч) и холодную деформацию.

В качестве исходных составляющих использовали взаимно нерастворимые друг в друге компоненты - сталь 3 и медь. На рис. 1 показаны образцы Шарпи с V-образным надрезом.

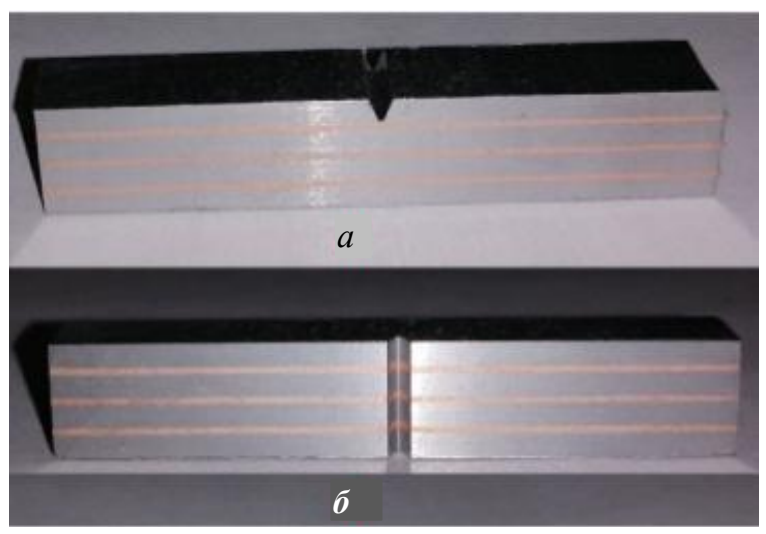

Рис. 1. Общчий вид образиов стали 3-меди М1 для испьтаний по Шарпи:

$a$ - параллельно слоям (торможение распространения трешины);

б - перпендикулярно слоям (разветвление трещины)

Образцы в сечении 9,5×9,5 мм длиной 55 мм в средней части имели надрез глубиной 2 мм с радиусом в основании 0,25 мм. Испытания проводились на моторизованном маятниковом копре INSTRON, модель S1-1M. Концентратор напряжений типа V наносили при помощи моторизованного станка для нанесения надрезов на заготовке образцов по Шарпи и Изоду. Производитель - RJW Ltd., модель - 1W-CN B34.

Химический состав и механические свойства исходных материалов в МСК

\begin{tabular}{|c|c|c|c|c|c|c|c|c|c|c|c|}
\hline \multirow[b]{2}{*}{ Материал } & \multicolumn{11}{|c|}{ Свойства } \\
\hline & $\mathrm{C}$ & $\mathrm{Si}$ & Mn & $\begin{array}{c}\text { Твердость } \\
\text { по Виккерсу, } \\
\frac{\text { кг }}{\mathrm{Mм}^{2}}\end{array}$ & $\begin{array}{c}\text { Предел } \\
\text { прочности, } \\
\text { МПа }\end{array}$ & $\begin{array}{c}\text { Предел } \\
\text { текучести, } \\
\text { МПа }\end{array}$ & $\begin{array}{l}\text { Ударная } \\
\text { вязкость } \\
\mathrm{KCV}, \frac{\text { Дж }}{\mathrm{cm}^{2}}\end{array}$ & $\begin{array}{c}\text { Пластичность, } \\
\%\end{array}$ & $\begin{array}{c}\text { Толщина, } \\
\text { мкм }\end{array}$ & $\begin{array}{c}\text { Количество } \\
\text { слоев }\end{array}$ & $\begin{array}{c}\text { Объемная } \\
\text { доля, \% }\end{array}$ \\
\hline Сталь 3 & $\begin{array}{c}0,14 \ldots \\
0,22 \\
\end{array}$ & $\begin{array}{c}0,12 \ldots \\
0,30 \\
\end{array}$ & $\begin{array}{c}0,4 \ldots \\
0,65\end{array}$ & 179 & 450 & 250 & 108 & 30 & 2100 & 4 & 86 \\
\hline Медь М1 & - & - & - & 86,7 & 250 & 110 & 170 & 56 & 400 & 3 & 14 \\
\hline
\end{tabular}


Испытуемые образцы предварительно заливались в бакелит на заливном прессе LECO PR $4 \mathrm{X}$, после подготавливались шлифы на шлифовально-полировальной установке LECO GPX 300

Исследуемая ударная вязкость и порог хладноломкости показывают значения вязкости и характеризуют надежность конструкционного материала. Образцы из МСК были подвержены различным термообработкам:

- $700{ }^{\circ} \mathrm{C}-2$ ч (низкий отжиг, остывание в печи);

- $750{ }^{\circ} \mathrm{C}-2$ ч (неполный отжиг, остывание в печи);

- $850{ }^{\circ} \mathrm{C}-2$ ч (полный отжиг, остывание в печи);

- закалка $850{ }^{\circ} \mathrm{C}$ в воду плюс отпуск при $170{ }^{\circ} \mathrm{C}$ в течение 1 ч.

После термической обработки образцы испытаны на ударную вязкость. Дополнительно приведены металлографические исследования структуры после каждой термообработки, определена микротвердость и средний размер зерна.

Твердость образцов измерялась на полуавтоматическом микротвердомере LECO LM700 АТ при нагрузке 50 г с выдержкой 14 c. Расстояние между уколами составляло три длины диагонали отпечатка. Структура образцов исследовалась на инверсионном металлографическом микроскопе OLYMPUS GX 51 при увеличении $\times 50 \ldots \times 200$.

\section{РЕЗУЛЬТАТЫ ИССЛЕДОВАНИЙ И ИХ ОБСУЖДЕНИЯ}

При анализе экспериментальных данных прочности МСК на основе стали 3 и меди M1, следует обратить особое внимание на изучение кинетики деформирования и разрушения этого класса материалов при различных температурах обработки. Предполагается, что результаты изучения кинетики разрушения, во многом зависящие от диффузии и адгезионных процессов, образования фаз и интерметаллидов на границе раздела компонент, дадут новую информацию не только о физике прочности МСК, но и о разрушении «гетерогенных» твердых тел $[11,12]$.

Металлографические исследования показали, что сталь 3 в МСК после отжигов при $700{ }^{\circ} \mathrm{C}$ (2 ч), $750{ }^{\circ} \mathrm{C}\left(2\right.$ ч) и $850{ }^{\circ} \mathrm{C}$ (2 ч) имеет ферритоперлитную структуру. При этом средний размер зерна при отжиге $700{ }^{\circ} \mathrm{C}\left(2\right.$ ч) - 62 мкм, $750{ }^{\circ} \mathrm{C}(2$ ч) - 67 мкм, $850{ }^{\circ} \mathrm{C}(2$ ч) $-66,5$ мкм (рис. 2$)$.

Определения соотношения перлита и феррита после различных режимов термообработки осуществляли по эталону микроструктуры ГОСТ 8233-56. При температуре отжига $700{ }^{\circ} \mathrm{C}$ (2 ч) соотношение перлита к ферриту $20: 80$; при $750{ }^{\circ} \mathrm{C}$ (2 ч) - 5:95; при $850{ }^{\circ} \mathrm{C}(2$ ч) - 35:65.

Феррит - твердый раствор углерода a-Fe, пластичный (твердость $\sim 80 \mathrm{HB})$, в виде светлых зерен (см. рис. 2). Перлит - эвтектоидная смесь феррита и цементита (твердость 160...260 НВ), темная составляющая.
Увеличение среднего размера зерна и изменения соотношения феррита к перлиту в стали 3 являются, на наш взгляд, основными факторами, влияющими на ударную вязкость при данных режимах термообработки. Значение ударной вязкости в образцах с надрезом параллельно слоям (торможение распространения трещины) несколько выше, чем в образцах - перпендикулярно слоям (разветвление распространения трещины) (рис. 3).

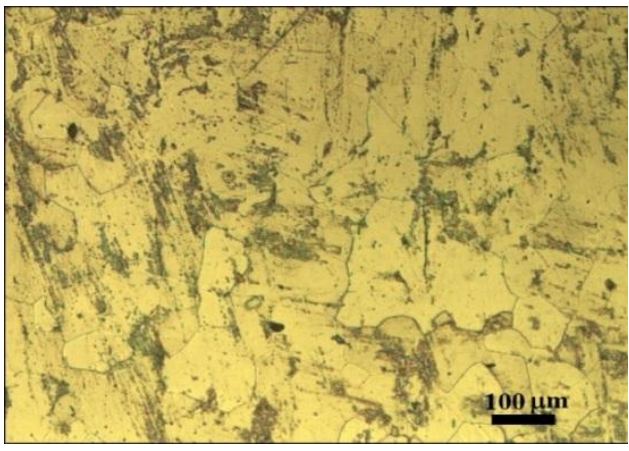

$a-T_{\text {отж }}=700^{\circ} \mathrm{C}(2$ ч)

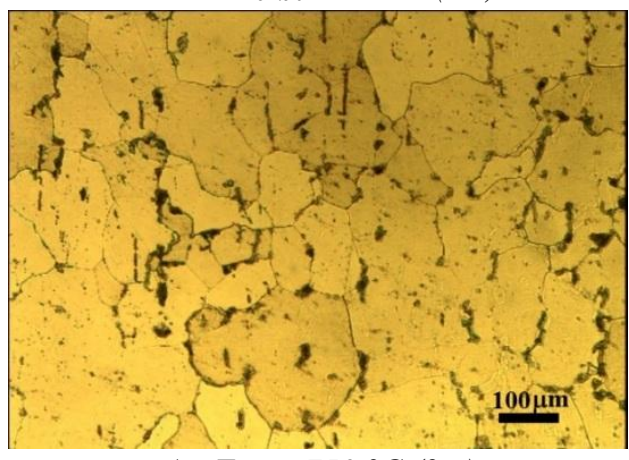

$\sigma-T_{\text {отж }}=750^{\circ} \mathrm{C}(2$ ч)

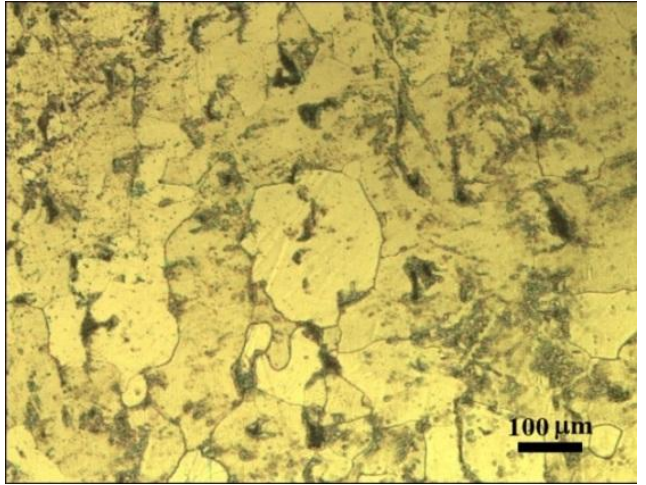

$8-T_{\text {отж }}=850^{\circ} \mathrm{C}(2$ ч)

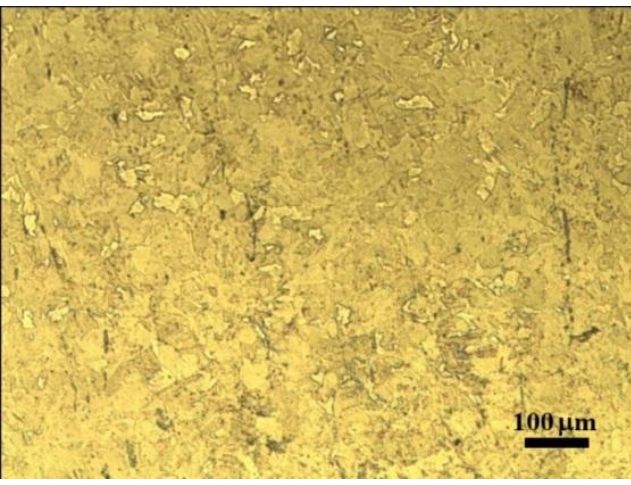

$2-T_{3}=850+170{ }^{\circ} \mathrm{C}(1 \mathrm{u})$

Рис. 2. Микроструктура стали 3 после различных термообработок 


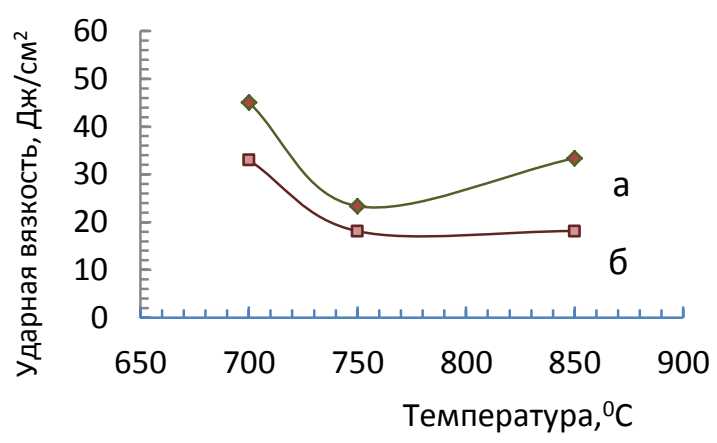

Рис. 3. Зависимость ударной вязкости $a_{n}$ от температуры отжига при надрезе торможения распространения (а) и разветвления трещиины (б)

Наряду с ростом зерна, при увеличении температуры отжигов и происходящими диффузионными процессами образования твердых растворов микротвердость является не менее важной характеристикой при испытаниях на ударную вязкость [13], а в случае с МСК - также и прокаливаемость (рис. 4). Микротвердость стали 3 после отжига при разных температурах (700, 750 и $850{ }^{\circ} \mathrm{C}-2$ ч) практически одинакова и изменяется в

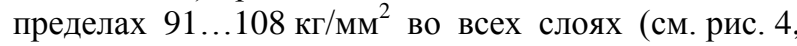
кривая 1).

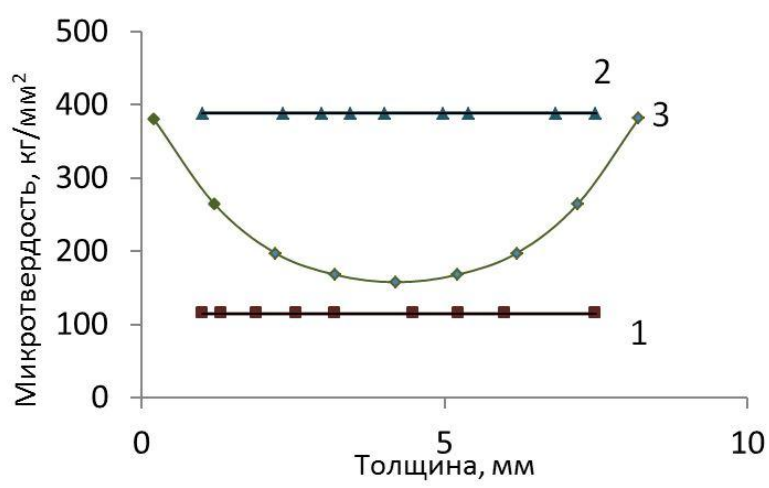

Рис. 4. Микротвердость по толщчине образия:

1 - отжиг при $750{ }^{\circ} \mathrm{C}$ (2 ч, остьвание в печи) образеи МСК; 2 - закалка при $850{ }^{\circ} \mathrm{C}$ в воду плюс отпуск при $170{ }^{\circ} \mathrm{C}(1$ ч) - образеи сталь 3; 3 - закалка при $850{ }^{\circ} \mathrm{C}$ в воду плюс отпуск при $170{ }^{\circ} \mathrm{C}(1$ ч) - образеи МCK

Испытания образцов после двойной термообработки (закалка при $850{ }^{\circ} \mathrm{C}$ в воду) плюс отпуск при $170{ }^{\circ} \mathrm{C}(1$ ч) на ударную вязкость имели значение ударной вязкости на уровне

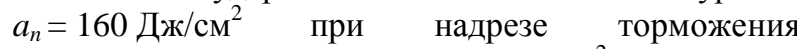
распространения трещины и 77 Дж/см² при надрезе разветвления трещины. При этом микротвердость HV составила 400 кг/мм², структура мартенситная, мелкозернистая, границы зерен отсутствуют (см. рис. 2, г).

Прокаливаемость МСК на основе стали 3 и меди M1 такая, как у габаритных деталей, - на поверхности твердость больше, а к центру меньше. Образцы стали 3 тех же размеров прокаливались насквозь (см. рис. 4, кривая 2). Образцы из МСК за счет медных прослоек прокаливались хуже (медные прослойки уменьшают скорость охлаждения при закалке). В центре образцы имели пониженные значения микротвердости (см. рис. 4, кривая 3), что также повлияло на значение ударной вязкости. Это необходимо учитывать при изготовлении изделий из МСК с последующей (если необходимо) закалкой.

\section{ВЫВОДЫ}

Термообработка при $850{ }^{\circ} \mathrm{C}$ (закалка в воду плюс отпуск при $170{ }^{\circ} \mathrm{C}$ в течение 1 ч) является наиболее оптимальной, поскольку при данной температуре наблюдается повышенное значение механических

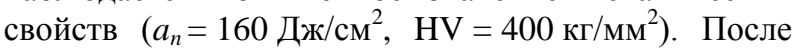
такой обработки ударная вязкость для МСК превышает значения ударной вязкости для стали 3 на $20 \%$.

1. Значение ударной вязкости МСК на основе стали 3 и меди М1, состоящих из семи слоев с объемной долей меди 14\%, при различных режимах термообработки (отжиг при разных температурах) существенным образом зависит от соотношения феррита к перлиту в микроструктуре стали 3 (объемная доля 86\%), а также от среднего размера зерна (феррита).

2. Микротвердость образцов металлических слоистых композитов на основе стали 3 (четыре слоя) и меди М 1 (три слоя) после двойной термообработки (закалка при $850{ }^{\circ} \mathrm{C}$ в воду плюс $\begin{array}{lllll}\text { отпуск при } 170{ }^{\circ} \mathrm{C} & (1 \text { ч) }) \text { уменьшается от }\end{array}$

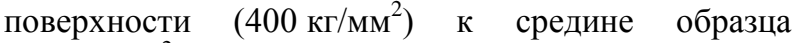
$\left(150 \mathrm{\kappa г} / \mathrm{MM}^{2}\right)$.

3. После двойной термообработки (закалка при $850{ }^{\circ} \mathrm{C}$ в воду плюс отпуск при $170{ }^{\circ} \mathrm{C}(1$ ч)) сталь 3 имеет мартенситную микроструктуру, границы зерен отсутствуют.

\section{БИБЛИОГРАФИЧЕСКИЙ СПИСОК}

1. І.М. Неклюдов, В.М. Воєводін, С.Ю. Діденко, М.І. Ільченко та інші. Наноструктуровані мікроламінати мідь-сталь: отримання та механічні властивості // Фізико-хімічна механіка матеріалів. 2011 , №3, c. $85-88$.

2. Ch. Ding, J. Xu, D. Shan, B. Guo, T. Langdon. Sustainable fabrication of $\mathrm{Cu} / \mathrm{Nb}$ composites with continuous laminated structure to achieve ultrahigh strength and excellent electrical conductivity // Composites Part B: Engineering. 2021, v. 211, p. 108662.

3. S. Zheng, I. Beyerlein, J. Carpenter, et al. Highstrength and thermally stable bulk nanolayered composites due to twin-induced interfaces // Nat Commun. 2013, N 4, p. 1696.

4. S. Satyam et al. Texture and Microstructure Evolution during Cold Rolling of $\mathrm{Cu}-\mathrm{Fe}$ Laminates Prepared by Accumulative Roll Bonding // Materials Science Forum. 2012, v. 715-716, Trans Tech Publications, Ltd., p. 170-170.

5. А.П. Гуляев. Металловедение. М.: «Металлургия», 1986, с. 544.

6. В.Р. Регель Проблемы физики композиционных материалов // Tезисы докладов VIII Всесоюзной конференции по физике прочности и пластичности металлов и сплавов. Куйбышев, 1976, c. 66-69. 
7. Б.С. Бокштейн, В.И. Внуков, Е.В. Голосов, М.И. Карпов. Структура и диффузионные процессы в слоистых композитах системы $\mathrm{Cu}-\mathrm{Ti} / /$ Известия вузов. 2009, №8, с. 60-65.

8. С.В. Гладковский, Т.А. Трушина, Е.А. Коковихин. Прочность и разрушения металлических композитов на основе меди М 1 и стали 20 // Машиностроение. 2010, с. 321-325.

9. С.Ю. Діденко, М.І. Ільченко, Н.Р. Рибальченко. Вакуумна прокатка: методи та перспективи розвитку. Сборник «Академік Віктор Свгенійович Іванов». 2002, с. 115-127.

10. И.М. Неклюдов, В.Н. Воеводин, С.Ю. Диденко и др. Механические свойства и структура микроламинатов системы медь-железо // Bonросы атомной науки $и$ техники. Серия «Физика радиачионных повреждений и радиационное материаловедение». 2010, №5, с. 89-94.
11. В.А. Белошенко, В.Н. Ворохин, В.Ю. Дмитренко. Волокнистые $\mathrm{Cu}-\mathrm{Fe}$-композиты, получение методом пакетной гидроэкструзии, структура, механические и резистивные свойства // Физика $и$ техника высоких давлений. 2010, №3, с. 110-119.

12. М.И. Карпов, В.П. Коржов, В.И. Внуков. Механические свойства многослойных композитов со слоями наноразмерной толщины // Деформация $u$ разрушение материалов. 2010, №12, с. 36-40.

13. М.Г. Лозинский, А.И. Тананов, А.М. Соковиков. Некоторые вопросы микромеханики разрушения плакированных слоистых металлических композиций // Tезисы докладов VIII Всесоюзной конференции по физике прочности и пластичности металлов и сплавов. Куйбышев, 1976, c. $69-70$.

\title{
ВПЛИВ РІЗНИХ РЕЖИМІВ ТЕРМООБРОБКИ НА УДАРНУ В' ЯЗКІСТЬ МЕТАЛЕВОГО ШАРУВАТОГО КОМПОЗИТУ (МШК) НА ОСНОВІ СТАЛІ 3 I МІДІ М1
}

\author{
В.М. Восводін, М.І. Ільченко, Г.Ю. Ростова, С.О. Крайнюк, О.М. Ільченко
}

Вивчено вплив попередньої термічної обробки на твердість, ударну в'язкість і прогартовуваність металевого шаруватого композиту на основі сталі 3 і міді М1. Були проведені дослідження мікроструктури отриманих композитів.

\section{EFFECT OF VARIOUS HEAT TREATMENT REGIMES ON THE IMPACT ELASTICITY OF A METAL LAYERED COMPOSITE (MLC) BASED ON STEEL 3 AND COPPER M1}

\author{
V.N. Voyevodin, N.I. Ilchenko, A.Yu. Rostova, Y.A. Krainyuk, O.N. Ilchenko
}

The effect of preliminary heat treatment on hardness, impact elasticity and hardenability of a metal layered composite based on steel 3 and copper M1 was studied. Studies of the microstructure of the obtained composites were carried out. 